\title{
GRAU DE COBERTURA DOS PLANOS DE SAÚDE E DISTRIBUIÇÃO REGIONAL DO GASTO PÚBLICO EM SAÚDE
}

\author{
Samuel Kilsztajn* \\ Dorivaldo Francisco da Silva** \\ Marcelo Bozzini da Camara** \\ Vanessa Setsuko Ferreira**
}

RESUMO: $O$ artigo analisa o grau de cobertura dos planos de saúde segundo as classes de rendimento mensal familiar e por unidade da federação e a distribuição dos recursos da Rede-SUS e do gasto público total em saúde por usuário dos serviços públicos de saúde nas regiões Norte-Nordeste e Centro-Sul do país. São apresentados e discutidos também os indicadores do gasto público total em saúde como percentual do PIB gerado nas regiões.

PALAVRAS-CHAVE: gasto público em saúde, economia da saúde, economia regional.

* Professor Titular da Pontifícia Universidade Católica - Área de Economia e Coordenador do Laboratório de Economia Social do Programa de Estudos Pós-Graduados em Economia Política - LES/PUCSP. Rua Monte Alegre, 984 CEP 05014901 São Paulo/SP.

** Alunos de Pós-Graduação (Mestrado e Doutorado) da Pontificia Universidade Católica - Área de Economia 


\section{INTRODUÇÃO}

O mercado supletivo de serviços de saúde no Brasil, que agrega planos de saúde administrados por autogestão, cooperativas, empresas de medicina de grupo e seguradoras, foi objeto de diversos estudos recentes na área da saúde (ALMEIDA, 1998, CORREA, PIOLA, \& ARILHA, 1998, VIANA \& PIOLA, 1999).

A divulgação da ampla pesquisa sobre as "Características de Saúde dos Moradores" realizada no âmbito da Pesquisa Nacional por Amostra de Domicílio de 1998 (IBGE, 2000) permite, entre outras estimativas, mapear a população residente coberta por planos de saúde segundo as classes de rendimento mensal familiar e por unidade da federação - UF.

O IBGE estimou em 38,7 milhões o número de pessoas cobertas por planos de saúde em 1998. As entidades representativas dos quatro segmentos do mercado supletivo de serviços de saúde apresentam estimativas que somam 46,7 milhões de beneficiários no país em 1999 (CIEFAS, 2000) e não divulgam estimativas por UF.

A partir das estimativas do IBGE para a população não coberta por planos de saúde pode-se calcular a distribuição dos recursos do SUS (Sistema Único de Saúde) e do gasto público total em saúde para a parcela da população que efetivamente se utiliza da RedeSUS e dos serviços públicos de saúde.

O presente estudo, além dos indicadores de gasto por usuário, discute as conclusões do trabalho de FERNANDES (1998), a partir das estimativas do gasto público total em saúde como percentual do PIB gerado em cada região.

De acordo com o grau de cobertura dos planos de saúde e da distribuição do gasto público total em saúde por UF, o Brasil, para efeito de análise, pode ser subdivido em dois grandes blocos, o Centro-Sul do país (Centro-Oeste, Sudeste e Sul) e a região Norte-Nordeste que apresenta o menor grau de cobertura dos planos de saúde, o menor gasto público total em saúde por usuário e os piores indicadores físicos de serviços de saúde do país (KILSZTAJN, 2000). 


\section{GRAU DE COBERTURA DOS PLANOS DE SAÚDE}

De acordo com a pesquisa do IBGE (2000), um quarto da população brasileira (24,4\%) possuía planos de saúde em 1998. Mas o grau de cobertura variava de $2,6 \%$ para a classe com até um salário mínimo de renda mensal familiar a $76,2 \%$ para a classe com mais de vinte salários mínimos (ver gráfico 1).

Por UF, o grau de cobertura dos planos de saúde variava entre 5,9\% no Maranhão e 39,2\% no Estado de São Paulo (ver gráfico 2). As UF com maiores graus de cobertura de planos de saúde encontram-se localizadas na região Centro-Sul do país e as UF com menores graus de cobertura na região Norte-Nordeste.

A diferença nos graus de cobertura por região, entretanto, pode levar a análises equivocadas sobre a distribuição da população que não tem acesso a planos de saúde e que depende portanto dos serviços públicos de saúde. Em termos absolutos, a região CentroSul é a que apresenta o maior número de pessoas cobertas por planos de saúde mas também é a que apresenta o maior número de pessoas não cobertas por planos de saúde (ver tabela 1).

A cobertura dos planos de saúde atingia $30,3 \%$ da população na região Centro-Sul do pais e $13,1 \%$ no Norte-Nordeste. O Centro-Sul do país, contudo, reunia $56,4 \%$ dos brasileiros com renda mensal familiar de até 5 salários mínimos que, como vimos, constitui a parcela da população com menor coberta dos planos de saúde no país. Para uma população estimada em 158 milhões em 1998, 96 milhões auferia uma renda mensal familiar de até 5 salários mínimos. Destes 96 milhões, 42 milhões residiam no Norte-Nordeste e 54 milhões na região Centro-Sul. Além disso, embora não se tenham estimativas do poder de compra da moeda por UF, sabe-se que o poder de compra da moeda na região Norte-Nordeste é superior ao poder de compra da moeda no Centro-Sul. Como o poder de compra de 5 salários minimos é maior no Norte-Nordeste que no Centro-Sul, a participação da população brasileira de baixa renda que reside no Centro-Sul encontra-se ainda subestimada.

A população não coberta por planos de saúde e que depende dos serviços públicos de saúde atingia 120 milhões em 1998, 47 milhões residentes no Norte-Nordeste e 73 milhões no Centro-Sul. A maior parte da população brasileira que não está coberta por planos de saúde residia portanto na região Centro-Sul do país. 


\section{DISTRIBUIÇÃO REGIONAL DO GASTO PÚBLICO TOTAL EM SAÚDE}

Vejamos agora como foram distribuídos regionalmente os recursos da produção ambulatorial e das internações na Rede-SUS. Alternativamente à ponderação dos valores repassados pelo SUS pelo número de habitantes de cada região, a pesquisa do IBGE, 2000 permite ponderar os recursos pela parcela da população que efetivamente se utiliza da Rede-SUS, isto é, pela população não coberta por planos de saúde. ${ }^{1}$

A tabela 2 apresenta o valor total repassado pelo SUS para a produção ambulatorial e internações hospitalares em 1998. O valor repassado pelo SUS por usuário na região Centro-Sul $(R \$ 77,83)$ foi $65 \%$ superior ao valor repassado por usuário na região NorteNordeste $(R \$ 47,27){ }^{2}$

O gasto público total em saúde por UF nas três esferas de governo (que inclui os valores repassados pelo SUS) foi estimado pelo IPEA (FERNANDES, 1998) para o ano de 1995. O gasto por origem dos recursos (gastos diretos e transferências negociadas) excluem amortizações das dividas, pessoal inativo, combate a carências nutricionais e gastos com saneamento do orçamento do Ministério da Saúde. Por outro lado, incluem gastos com saúde de outros ministérios, notadamente do Ministério da Educação (responsável pelos hospitais universitários). ${ }^{3}$

A tabela 3 apresenta o gasto público total em saúde nas esferas federal, estadual e municipal e por usuário, isto é, ponderado pela população sem plano de saúde. Para o cálculo da população sem plano de saúde em 1995 aplicamos o grau de cobertura dos planos de saúde em 1998 às estimativas da população utilizadas pelo estudo do IPEA para 1995. De acordo com a tabela 3, o gasto público em saúde por usuário nas três esferas de governo na região Centro-Sul $(R \$ 203,81)$ era o dobro do gasto por usuário na região NorteNordeste $(\mathrm{R} \$ 101,02)$.

\footnotetext{
1 Este procedimento é preferivel ao da parcela da população que utilizou o plano de saúde em atendimento nas duas últimas semanas e na última internação em 12 meses.

2 Se ao invés da população sem plano de saúde utilizássemos como denominador a população total de cada região, o valor repassado pelo SUS per capita na região Centro-Sul $(\mathbf{R} \$ 54,24)$ seria $32 \%$ superior ao valor repassado per capita na rcgião Norte-Nordeste $(\mathrm{R} \$ 41,10)$.

30 gasto público federal em saúde estimado em FERNANDES (1998), não inclui também a assistência médico-odontológica a servidores públicos (contabilizados como gastos sociais na forma de beneficios a servidores).
} 
Embora o gasto público total em saúde por usuário da região Centro-Sul tenha sido o dobro do gasto por usuário da região Norte-Nordeste, a pesquisa do IPEA aponta a maior concentração do gasto público total em saúde na região Norte-Nordeste. A tabela 10 da pesquisa do IPEA (FERNANDES, 1998, p. 27) destaca que, em 1995, o gasto público total em saúde representava 3,3\% do PIB gerado na Região Norte do país e $4,5 \%$ do PIB do Nordeste, enquanto que o gasto público total em saúde representava apenas $2,4 \%$ do PIB gerado na Região Sul, $2,7 \%$ no Sudeste e $3,2 \%$ no Centro-Oeste. A pesquisa utiliza o gasto público ponderado pelo PIB gerado em cada região e considera que este indicador "sugere um esforço de políticas púbicas para a diminuição das desigualdades sociais" (FERNANDES, 1998, p. 25).

Os dois indicadores de gasto público total em saúde acima citados, aparentemente contraditórios, podem induzir a conclusões conflitantes. Dissemos aparentemente contraditórios porque os dois indicadores utilizam o mesmo numerador, o gasto público total em saúde. Entretanto o primeiro indicador utiliza como denominador a população não coberta por plano de saúde enquanto que o segundo indicador utiliza como denominador o PIB gerado em cada região. Poderíamos adicionar ainda um terceiro indicador, o de gasto público total em saúde por habitante ( $R \$ 87,82$ p/hab no Norte-Nordeste e $R \$ 142,04$ p/hab no CentroSul).

Para visualizar a diferença dos três indicadores, construímos o gráfico 3 que apresenta o indicador de gasto por usuário, o indicador de gasto por habitante e o PIB per capita para cada uma das regiōes analisadas. De acordo com as estimativas do IPEA, 0 PIB per capita gerado na região Centro-Sul em 1995 (R\$5224) era duas vezes e meia o PIB per capita gerado na região Norte-Nordeste no mesmo ano (R2121). Desta forma, mesmo com um gasto público total em saúde por habitante significativamente menor, o gasto de $\mathrm{R} \$ 87,82$ por habitante no Norte-Nordeste em relação ao PIB per capita de $\mathrm{R} \$ 2121(4,1 \%)$ é percentualmente maior que o gasto de $\mathrm{R} \$ 142,04$ por habitante no Centro-Sul em relação ao PIB per capita de $\mathrm{R} \$ 5224(2,7 \%)$.

Quando introduzimos o indicador por habitante, o gasto público total em saúde da região Centro-Sul passa a ser $62 \%$ superior ao da região Norte-Nordeste. Como o grau de cobertura dos planos de saúde é menor no Norte-Nordeste, quando passamos para o indicador por usuário da rede pública, a população que efetivamente se utiliza dos serviços públicos de saúde, o gasto público total em saúde do Centro-Sul passa a ser $102 \%$ superior ao do Norte-Nordeste (ver gráfico 3). 
O gasto público em saúde por usuário na região Centro-Sul é superior ao gasto por usuário na região Norte-Nordeste em todas as três esferas de governo, sendo que a diferença é mais significativa na esfera estadual e principalmente na esfera municipal (ver tabela 3). Mas o gasto público federal em saúde (R\$13,7 bilhões) representava $63 \%$ do gasto público total em saúde em 1995 ( $R \$ 21,7$ bilhões) e, para um sistema que se pretende promotor da equidade social em nivel nacional, o gasto federal, ao invés de privilegiar as regiões mais ricas do pais, deveria corrigir as diferenças nos gastos públicos propiciadas pelos gastos dos governos estaduais e municipais relativamente mais ricos.

\section{CONSIDERAÇÕES FINAIS}

A partir dos dados da PNAD de 1998, que permitem a ponderação dos valores repassados pelo SUS e do gasto público total em saúde pelo número de usuários dos serviços públicos de saúde por UF, pode-se concluir que a distribuição regional do gasto público em saúde apresenta um perfil perverso, na medida em que privilegia as regiões mais ricas do pais e penaliza as regiões mais carentes. Como os indicadores de serviços de saúde ponderados pela população total de cada uma das regiões (KILSZTAJN, 2000) apontam também que todos os serviços de saúde por habitante são mais precários na região Norte-Nordeste do pais, pode-se afirmar que existe um circulo vicioso entre, por um lado, o número de médicos, outros profissionais da área da saúde, equipamentos e instalações disponiveis e, por outro, a possibilidade das regiões mais pobres do pais absorverem verbas públicas para a saúde. Neste sentido, acreditamos que devam ser reforçados os projetos e as iniciativas que possam atrair, ao mesmo tempo, investimentos, profissionais e verbas para as áreas mais carentes do país.

\section{REFERENCIAS BIBLIOGRÁFICAS}

ALMEIDA, C. O mercado privado de serviços de saúde no Brasil: panorama atual e tendências da assistência médica suplementar. Brasília, IPEA, 1998. (Texto para Discussão $n^{\circ}$ 599). Disponivel: http://www.ipea.gov.br

CIEFAS (Comitê de Integração de Entidades Fechadas de Assistência à Saúde Nacional). A história da autogestão em saúde no Brasil. São Paulo, CIEFAS, 2000.

CORREA, S., PIOLA, S., ARILHA, M. Cairo em ação: estudo de caso Brasil. Brasília, IPEA, 1998. 
FERNANDES, M.A.C. et al. Gasto social das três esferas de governo - 1995. Brasília: IPEA, 1998. (Texto para Discussão $n^{\circ} 598$ ). Disponivel: http://www.ipea.gov.br

FUNDAÇÃO IBGE. Acesso e utilização de serviços de saúde - 1998. Rio de Janeiro, IBGE, 2000.

KILSZTAJN, S. \& SILVA, D.F. Distribuição regional dos serviços de saúde no Brasil. In: Encontro Nacional de Estudos Populacionais, 12, 2000, Caxambu. Anais... Recife, ABEP, 2000.

SIA - Sistema de informações ambulatoriais. Disponível: http://www.datasus.gov.br [01.SET.2000].

SIH - Sistema de informações hospitalares. Disponivel: http://www.datasus.gov.br [01.SET.2000].

VIANA, S.M. \& PIOLA, S.F. Descentralização e gestão do gasto público com saúde no Brasil. In: CEPAL. Taller sobre evaluacion de la gestión del gasto público en salud. Brasilia, CEPAL, 1999. 
1 - População e Cobertura de Plano de Saúde *

\begin{tabular}{lllll}
\hline & até $5 \mathrm{sm}$ & $>5$ a 20 sm & $>20 \mathrm{sm}$ & total \\
\hline População Total & 95676 & 52420 & 10136 & 158232 \\
$\begin{array}{l}\text { Norte - Nordeste } \\
\text { Centro - Sul }\end{array}$ & 41725 & 10444 & 1618 & 53786 \\
& 53951 & 41977 & 8518 & 104446 \\
Com Plano de Saúde & 9474 & 21489 & 7721 & 38683 \\
Norte-Nordeste & 2317 & 3570 & 1141 & 7027 \\
Centro - Sul & 7157 & 17919 & 6580 & 31656 \\
& & & & \\
Sem Plano de Saúde & 86203 & 30932 & 2415 & 119549 \\
Norte - Nordeste & 39408 & 6874 & 477 & 46759 \\
Centro - Sul & 46795 & 24058 & 1938 & 72790 \\
\hline
\end{tabular}

Fonte: elaborado a partir de IBGE, 2000

* de acordo com a análise do grau de cobertura: a população sem declaração de rendimentos foi incluída em $>5$ a $20 \mathrm{sm}$; a população sem rendimentos, pensionistas, empregados domésticos, parentes de empregados domésticos e sem declaração de cobertura de plano de saúde foi incluída em até $5 \mathrm{sm}$; não inclui a população rural da Região Norte (exceto Tocantins).

2 - Valor repassado pelo SUS

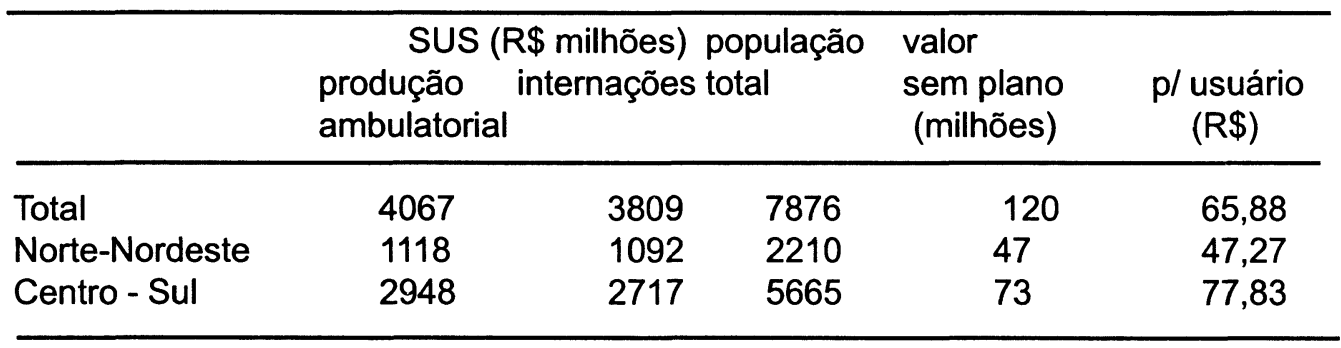

Fonte: elaborado a partir de SIA, 2000, SIH, 2000 e tabela 1. 
3 - Gasto Público em Saúde - 1995

\begin{tabular}{|c|c|c|c|c|}
\hline & federal & estadual & municipal & total \\
\hline & \multicolumn{4}{|c|}{ gasto total ( $\mathrm{R} \$$ milhões) } \\
\hline Total $^{*}$ & 13686 & 4492 & 3559 & 21738 \\
\hline Norte-Nordeste & 3175 & 1107 & 597 & 4880 \\
\hline \multirow[t]{2}{*}{ Centro-Sul } & 7885 & 3385 & 2962 & 14232 \\
\hline & & \multicolumn{3}{|c|}{ valor por usuário (R\$) } \\
\hline Total $^{\star *}$ & 116,30 & 38,17 & 30,25 & 184,71 \\
\hline $\begin{array}{l}\text { Norte-Nordeste } \\
\text { (a) }\end{array}$ & 65,74 & 22,91 & 12,37 & 101,02 \\
\hline $\begin{array}{l}\text { Centro-Sul (b) } \\
\text { (b)/(a) }\end{array}$ & $\begin{array}{l}112,91 \\
171,8 \%\end{array}$ & $\begin{array}{l}48,47 \\
211,6 \%\end{array}$ & $\begin{array}{l}42,42 \\
343,0 \%\end{array}$ & $\begin{array}{l}203,81 \\
201,8 \%\end{array}$ \\
\hline
\end{tabular}

Fonte: elaborado a partir de FERNANDES, 1998 e IBGE, 2000

* inclui R\$ 2,6 milhões de gastos federais em nivel nacional.

** inclui $R \$ 22,32$ de gastos federais em nivel nacional. 


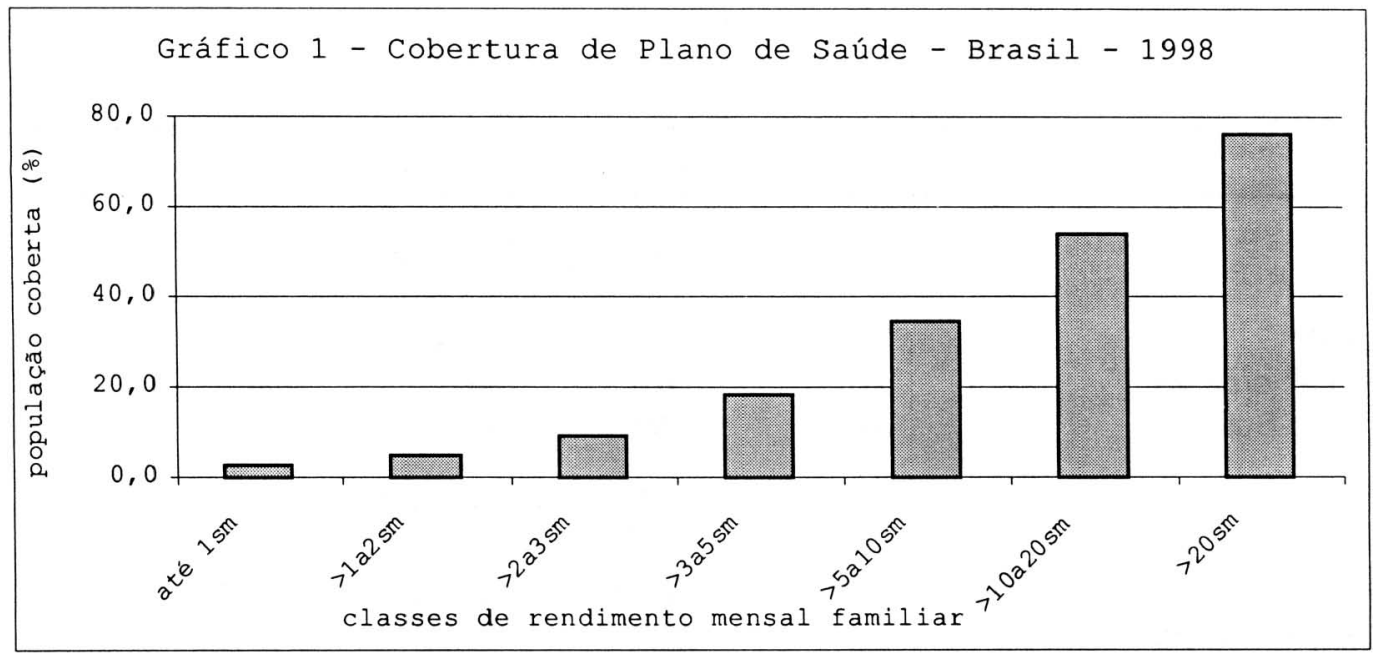

Fonte: elaborado a partir de IBGE, 2000.

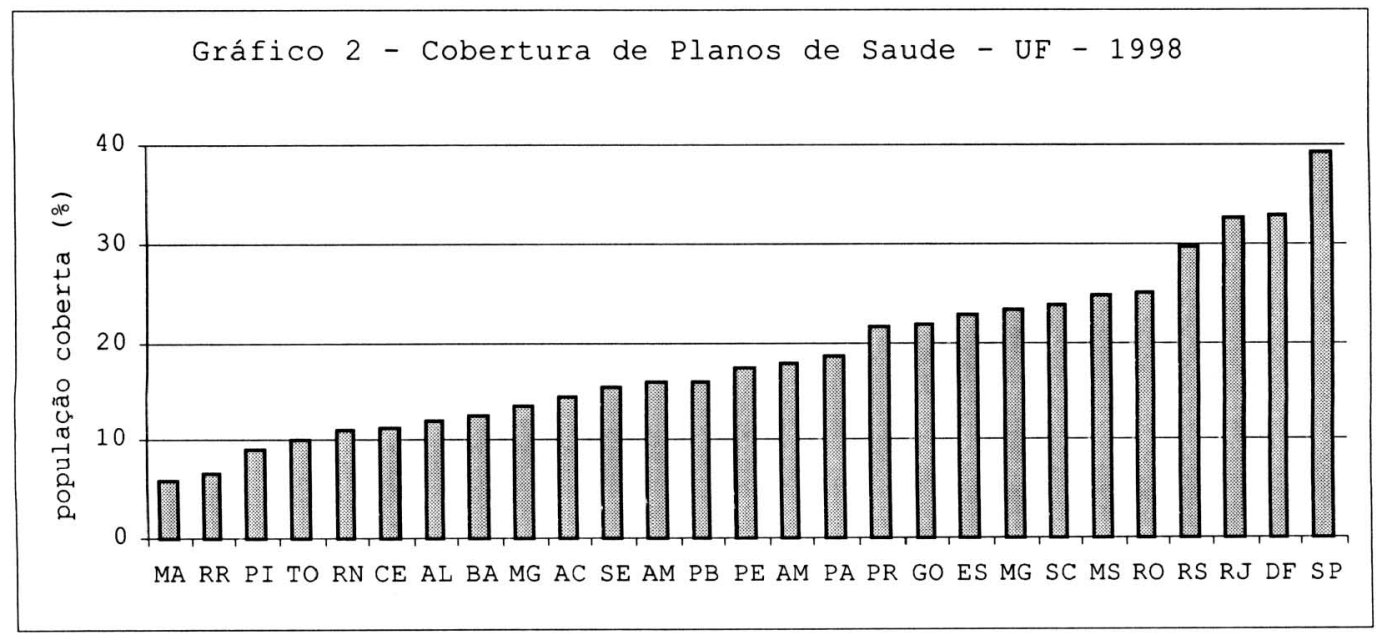

Fonte: elaborado a partir de IBGE, 2000 


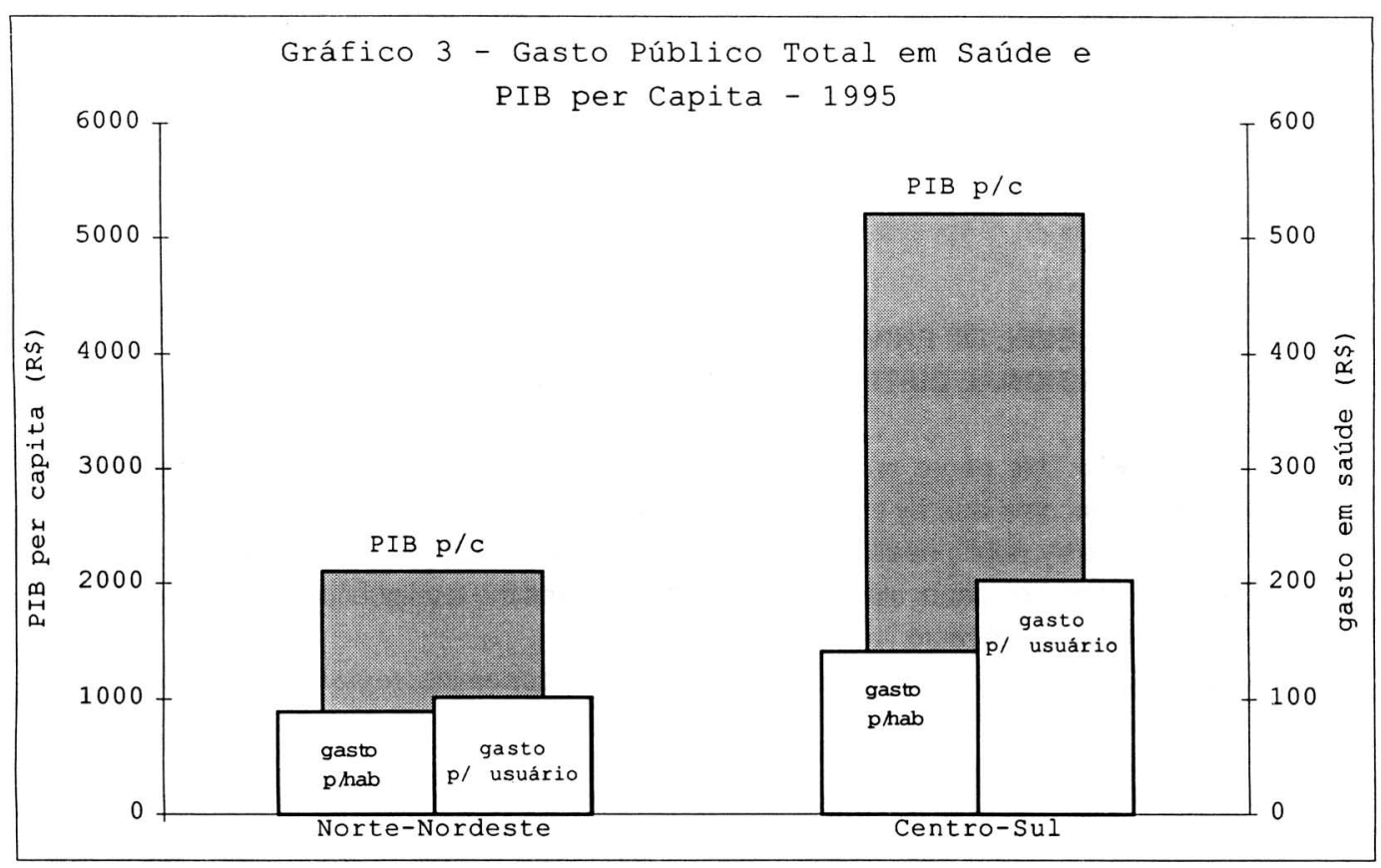

Fonte: elaborado a partir de IBGE, 2000 e Fernandes, 1998. 


\section{LEVEL OF PRIVATE HEALTH INSURANCE COVERAGE AND REGIONAL DISTRIBUTION OF PUBLIC HEALTH EXPENDITURE}

SUMMARY: This paper analyses the level of private health insurance coverage by classes of income and by states in Brazil and the distribution of the total public health expenditure by public health users in the North-Northeast and Central-South regions of the country. The paper also presents and discusses the total public health expenditure as a percentage of regional GDP.

KEY WORDS: public health expenditure, health economics, regional economics. 